\title{
Advantages and disadvantages of using computers in education and research
}

\section{Anna Consortini}

Anna Consortini, "Advantages and disadvantages of using computers in education and research," Proc. SPIE 9289, 12th Education and Training in Optics and Photonics Conference, 92891Q (17 July 2014); doi: $10.1117 / 12.2070557$

SPIE Event: 12th Education and Training in Optics and Photonics Conference, 2013, Porto, Portugal 


\title{
Advantages and disadvantages of using computers in education and research
}

\author{
Anna Consortini \\ Universita' degli Studi di Firenze, Dipartimento di Fisica, \\ Via G. Sansone 1, 50019 Sesto Fiorentino - Firenze, Italy, \\ emailanna.consortini@unifi.it,
}

\begin{abstract}
Use of computers in education and research has completely changed the way things were made before. For example, a lecture to the students or the presentation of a paper to a Congress are completely different with respect to those of only a few decades ago, when blackboard, transparencies or photographic slides were used. There are many positive aspects of using computers, for example making a talk very attractive. However, there are also negative aspects. In this paper an analysis is presented of advantages and disadvantages I experienced and of consequences of using computers.
\end{abstract}

Keywords: Computer in research, computer advantages, conservation issue

\section{INTRODUCTION}

This paper presents some considerations on the basis of my personal experience and does not pretend to give general results or rules. The advantages and disadvantages are those that I experienced in many years of activity, started when computers for research and teaching were not yet available.

Speaking of computers, from now on, I mean electronic computers. It should be noted that electronic computers were not a sudden invention, but they were the (provisional) "end" of the evolution of many different kinds of computation devices that were developed in the past, starting from the well known ancient abacus (or counting-frame or countingtable) used since the ancient Chinese, Greeks and Romans, up to the electro-mechanical devices used for computations just before the advent of the electronic computers.

I began doing research and teaching in the early 60'ties, just when "computers" became available. The computers were very large in "volume", that was really huge, as large as rooms, and very expensive. Only big entities, like for instance an industry or a University, were able to afford buying or renting one of them. On the contrary, the memory and capabilities were very small compared with the present ones.

Initially, computers, like all previous devices, were suitable just "for computations". They became useful for writing much later, when personal computers were introduced.

One first question is: advantages and disadvantages with respect to what?

Here I consider several subsequent steps: each one with respect to the previous one:

1 - when computers useful for computations were introduced, with respect to no-computers, in old times

2 - with respect to the first computers, during the evolution of them, when user friendly and easy to program software was developed and when larger computers were introduced,

3 - when sensing and in general measuring instruments for use with computers were built

4 - when personal computers were introduced, with writing facilities and use for teaching

5 - recent times, internet and so on.

12th Education and Training in Optics and Photonics Conference, edited by

Manuel F. P. C. Martins Costa, Mourad Zghal, Proc. of SPIE Vol. 9289, 92891Q

(C) 2014 SPIE, OSA, IEEE, ICO · doi: 10.1117/12.2070557

Proc. of SPIE Vol. 9289 92891Q-1 


\section{THE ADVENT OF ELECTRONIC COMPUTERS}

Introduction of electronic computers set an enormous discontinuity with respect to the times when they were not available.

I made my thesis for the University degree in a laboratory of Centro Microonde (subsequently IROE-CNR and now IFAC-CNR), a research centre of the National Research Council (CNR). When I started working on my first degree thesis in 1958, computers were not yet available in the University or the CNR, although in Italy the famous Olivetti Elea $\underline{9003}$ was soon in use.

The name Elea was from ELaboratore Elettronico Aritmetico, (Arithmetic electronic elaborator). Elea 9003 was the first computer using transistors only. Elea was also the name of an old city of Magna Graecia (precisely Lucania, south Italy) seat of a Greek school of Philosophy. One user of Elea, Luigi Logrippo, who worked in the Olivetti Computer Marketing Division, 1961-1964, remembers: "The Olivetti Elea 9003 was the first industrial electronic computer made in Italy. [...] The first operational specimens were installed in 1960, and the last in 1964. About 40 were produced [...] Just as other computers of the time, this one was a ... dinosaur. It occupied large, air-conditioned rooms [...] A cabinet included main memory and CPU (additional cabinets were required for memory extensions). Another cabinet was the control unit for the tape units. A third cabinet would contain the control unit for other peripherals, such as the printer [...] "Happily, the machine looked good because it was designed by a famous architect, Ettore Sottsass".

\subsection{Our first use of computer: the University computer}

The first computer in the University of Florence was an IBM 1620, with $20 \mathrm{~K}$ memory positions. It was located in the main building of the University, where the Dean and the Administrative offices lay and still lie. It was a large equipment, constituted by several different pieces, and was located in a large, locked room.

The different, scientific Institutes of the University were given access to it two hours on turn, during the day, according to a precise schedule established every month by the Director of the Institute of Astronomy.

I started working there as representative of the Institute of Electromagnetic Waves (Istituto di Onde Elettromagnetiche) of the University and was able to utilize every time the entire two hours, because there were no other people interested in it in the Institute. Sometimes it was possible to exchange hours with the previous and/or the following user and had up to four or also six hours of computer availability. This was very useful because the use of the computer was long and cumbersome.

IBM 1620 worked with cards: the input was given by cards and the output was on cards. There was a card writer (holes) and a large printer that printed on paper the output from the cards.

Programming was in Fortran, one of the first versions. There were subroutines for simple functions $\sin (\mathrm{x}), \cos (\mathrm{x})$, $\operatorname{atan}(\mathrm{x}), \exp (\mathrm{x}), \log (\mathrm{x}), \operatorname{sqrt}(\mathrm{x})$. On the contrary, integrals needed to be programmed by the users, on the basis of different approximate formulas. Generally, I wrote subroutines based on the integration method of Gauss. Once the program was written and the cards were punched, the card bundle (Source program) was inserted in the computer, together with a Processor program card bundle, which was used by the computer to translate the Source program in Computer Language. This gave rise to another set of cards (Object Program) which was then used for the computation.

Every time there was an error in the program, one had to find the error, replace the suitable cards in the Source Program and repeat all the procedure.

For those who never saw these things before, bundles of cards are shown on the left side of Fig.1.

We also started teaching programming in Base language and in Fortran language to higher level students. The right side of Fig. 1 shows the cover and one page of the notes of a course on computer, Post Doc School in Physics 1966. 

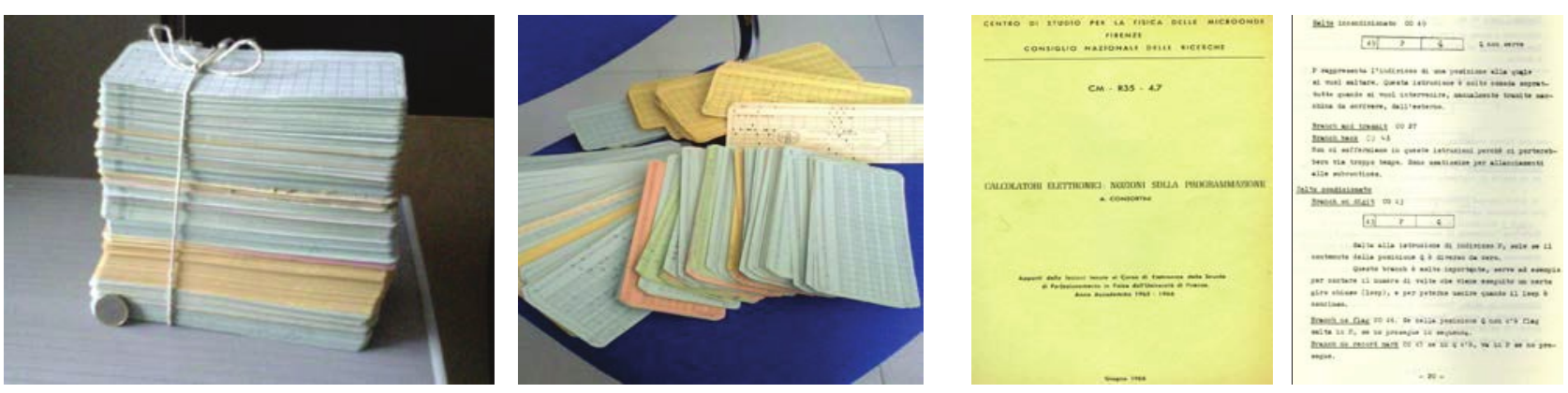

Fig. 1- Left: bundles of cards used for use with computer: old source program and cards with data for elaboration. Dimension reference: coin of one euro. Right: cover and one page of a course on Basic and Fortran languages

\subsection{Advantages of the introduction of computers: big step for computations}

In spite of the complex and cumbersome procedure of preparing the programs, the introduction of computers made a big step for the research, both for theoretical applications and for the elaboration of experimental data, as we will see in the sequel.

Programming these small computers required direct control of the different steps. One had to take the small memory and low velocity into account and to find suitable compromises between the different needs. In my opinion, this allowed a clear understanding of what was going on step by step, with the possibility of making changes and corrections. This also was an important point for the students, who learned programming, because they were faced to solve new problems and find optimum solutions.

As an example of our first use of the University computer, I was able to develop an iterative procedure on the IBM 1620 that allowed evaluation of modes and losses of a laser resonator, introduced by G. Toraldo di Francia, the so called flatroof resonator. Toraldo developed an approximate theory, based on a "diamond cavity" giving rise to modes: amplitude and phase. Starting from his theoretical field distribution, we tested the theory, and found losses and phase shifts, that were not given by the theory. The results were published in a joint issues of Applied Optics and Proc IEEE in 1966.

As an example, Fig. 2 shows: on the left side the scheme of the resonator; and, on the right side, the evolution of the amplitude of the field, at an arbitrary point, $\mathrm{x}=0.554$, over the normalized aperture. The amplitude was plotted versus

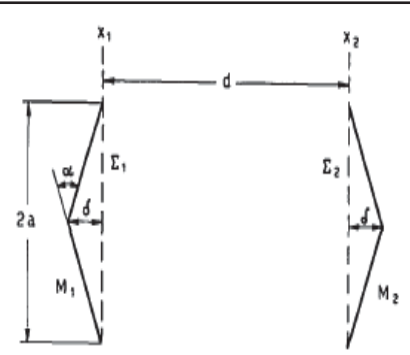

Fig. 3. Normal cross section of the infinite strip roof resonator.

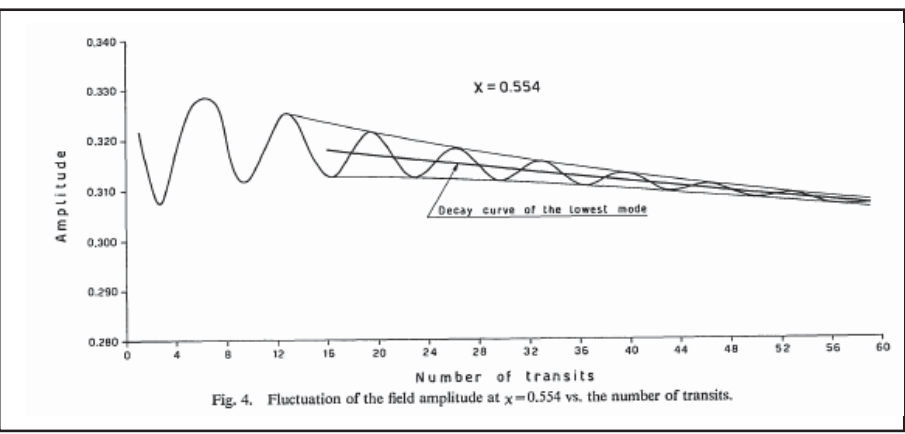

Fig. 2 - from Fig 3 and 4 of P.F. Checcacci, A. Consortini, A.M. Scheggi: Modes, Phase Shifts and Losses of Flat-Roof Resonators Joint Issue Applied Optics, 5, 1567 (1966) - Proceedings of the IEEE, 54, 1329 (1966)

the number of the iterative steps and showed an interference between the fundamental mode $(\mathrm{m}=0)$ and the second even mode $(\mathrm{m}=2)$. This allowed us to derive information on the second, even mode $(\mathrm{m}=2)$. 


\section{INTRODUCTION OF LARGE COMPUTERS IN ITALY}

After the "small" computer of our University, in Italy two big centres for computing became available.

In 1965 the CNUCE (Centro Universitario Nazionale Calcolo Elettronico) in Pisa was set up by the University of Pisa in collaboration with the IBM, which donated a computer IBM 7090. Subsequently CNUCE became a CNR Institute.

In 1969 CINECA, a Centre founded by a Consortium of the Universities of Bologna, Florence, Padua and Venice started the activity with a CDC 6600 Computer in Casalecchio di Reno, near Bologna. This Centre, initially devoted to computations, developed largely in the subsequent and recent years and now is the largest Italian computing centre and one of the most important worldwide. It is equipped with some of the largest supercomputers. Cineca is now a non-profit Consortium of 68 Italian universities and 3 Institutions, including CNR and MIUR, Ministry for Education and Research. Cineca offers support to the research activities of the scientific community through supercomputing and its applications.

\subsection{Our advances with use of large computers.}

In the 70ties, the use of large computers of CNUCE and CINECA allowed us to:

- improve and enlarge the iterative procedure and find solutions of the flat roof resonator in cases out of the theoretical approximation limit of Toraldo's theory;

- extend the iterative procedure to other kind of resonators, in particular resonators with very low losses, such as rimmed ones, and to obtain more complete results, including unstable regions;

- investigate the accuracy of different diffraction formulas (Applied Optics 1978). We showed that the proper angular dependence needs to be taken into account to obtain results with physical meaning in laser cavities investigation. (A. Consortini, F. Pasqualetti: Comparison of Various Diffraction Formulas in a Study of Open Resonators - Applied Optics $\underline{17}$, 2519, 15 Aug. 1978)

- develop and use methods to remove low order modes. For example, in the case of a Fabry-Perot resonator, we evaluated up to 26 modes (A. Consortini, F. Pasqualetti: An Analysis of the Modes of Fabry-Perot Open Resonators Optica Acta 20, n.10, 793-803, 1973 ).
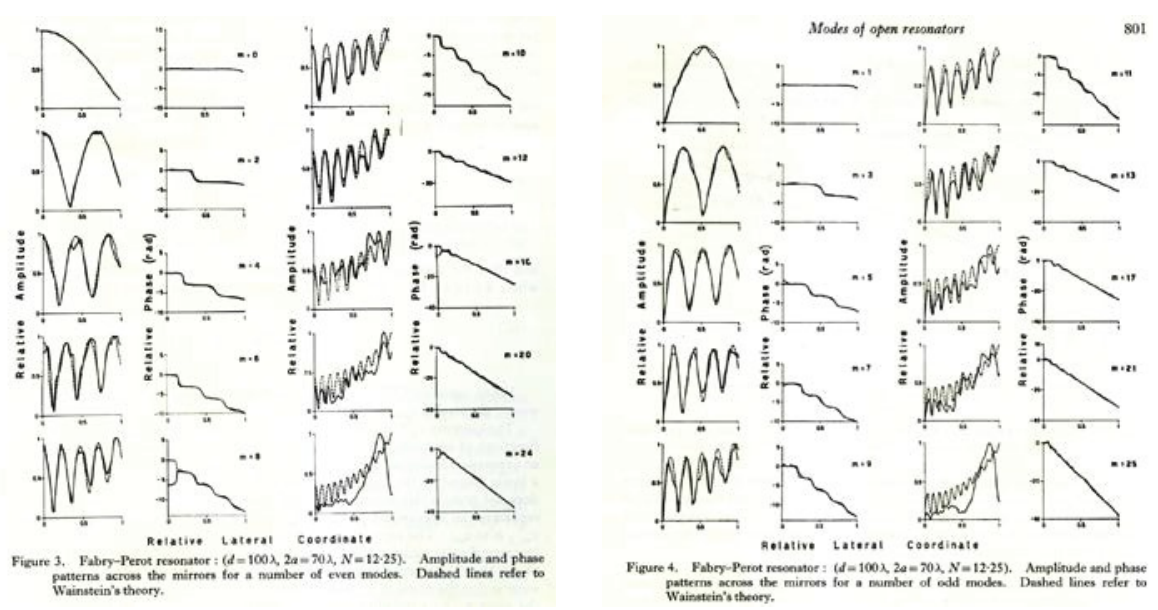

Fig. 3 Amplitude and phase patterns of 26 modes of a Fabry-Perot resonator. Left: even modes 0-24, Right: odd modes 1-25.

In Fig. 3 amplitudes and phases are presented of 26 modes of a Fabry-Perot resonator, with mirror aperture $2 \mathrm{a}=70 \lambda$, mirror distance $\mathrm{d}=100 \lambda$, Fresnel number $\mathrm{N}=12.25$ (from Optica Acta 1973). On the left hand side even modes and on the right one odd modes. Dashed lines are from Wainstein's theory. These results were exceptional ones also for the time when they were obtained. There were many other theoretical problems where we took great profit from computers, here we limit ourselves to the previous few examples and move to the next step.

Of course our experience is a small drop with respect to the general use, and I just want to mention here use and progress of computers for many theoretical problems, including applications to simulation. 


\section{COMPUTER AND MEASUREMENT INSTRUMENTS}

A big step in the computer use for research was when instruments linkable with computers became available. Now in any laboratory this is an obvious facility, but it was not so when we made experiments in the 70ties. Here below two examples from our research activity are described.

\subsection{Measurements of laser intensity fluctuations}

Initially, the output signal from an instrument was an analogical signal, that had to be digitized to be inserted in the computer. Therefore, one was faced to several different steps.

To describe the procedure, let us refer as an example to experiments we made in 1974. We made measurements of intensity fluctuations of laser radiation after an atmospheric path of about $4 \mathrm{~km}$. We focussed the radiation with a lens and collected it with a photomultiplier. We needed the following operations:

-the signal from the photomultiplier was continuously recorded on the magnetic tape of a Sabre Sangamo III Recorder (a very good instrument at that time), then

-it was digitized by an IBM System 7, at a rate of 2000 data/s and the digitized signal was recorded on a magnetic tape.

- the digitized signal was then used with a different computer to evaluate its average, moments up to the fourth one, and to built intensity histograms.

Years later, it was possible to connect the photomultiplier directly to a small computer, Apple, and have the data digitized and stored on it. There was the disadvantage that the memory was not as large as it is now, and initially the computer memory limited the amount of data to be collected. We had to find suitable compromises, but we were able to make measurement and data elaboration with the same computer.

\subsection{Position measurements}

An important case of use of instruments directly connected with the computer was measurement of positions. We needed position measurement for research on:

1 - angle of arrival fluctuations (often denoted as differential angle of arrival fluctuations) at points of a laser wavefront after a path through the atmospheric turbulence, and

2 - wandering of thin beams after a short path in the atmosphere.

As an example, let us here refer to angle of arrival. Laser radiation after a path through turbulence impinged on a holed mask, Hartmann test, giving rise to a set of thin beams. Due to turbulence, each beam fluctuated around an unperturbed position, and measurement of the instantaneous positions at different times was required to obtain the angle of arrival at the output of each hole.

When position sensors were not available, we let the beams impinge on a diffusing screen and took pictures of it by using a good photographic camera, Hasselbladt $500 \mathrm{EL}$, that, with suitable shrewdness like pre-exposure, allowed us to take pictures at a rate of $1 / \mathrm{s}$ with an exposure time of $1 / 500 \mathrm{~s}$. An experiment lasted from 5 up to 15 minutes. The photos were then developed.

In Fig. 4 the scheme of the measurement in the laboratory is presented as well as a photogram of the developed film.

Each measurement gave rise to from several hundreds up to about 500 photos. The position of each spot was then manually determined by using a projector. The procedure of "reading" the photos was very long and cumbersome and different people, typically 2 or 3 people, separately read the coordinates of the centres of the spots in order to reduce the operator's error. The data were printed and then used for a statistic elaboration with a small computer. The procedure required many months and patience of the scientists involved. 

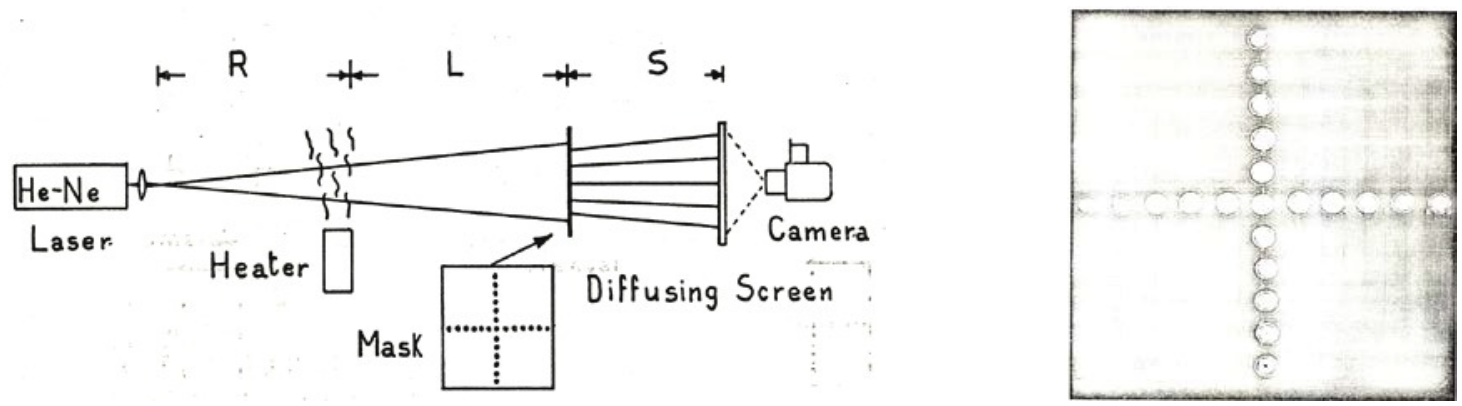

Fig. 4 Left: Scheme of experiment for angle of arrival measurement. Right a photogram. From: A. Consortini "Measurements of angle of arrival fluctuations of a laser beam due to turbulence" AGARD Conference Proceedings CP.183, 1986, pg 26.1-28.8, Fig.s 2 and 4.

When position sensors connectable with computer became available, collection of the data became a completely different job. Initially, there was still the limitation on the amount of data, but the problem was overcame with the development of personal computers of large memory and of suitable laboratory software.

To have an idea of the big improvement, an example is here reported of the final solution, that we reached in the 90ties, of the use of position sensors for measurement of beam wandering. The problem was analogous to the previous one. With a suitable program developed by us, the four signals from any sensor were directly introduced in the computer and the position automatically detected and recorded. Four sensors were connected to a simple PC. A program for "calibration" allowed to regulate the intensity and alignment of the sensors, with options for some on-line averages, another one called "acquisition" allowed the measurement, with a number of options, and a set of "elaboration" programs allowed off line statistic elaboration. All programs allowed use of from one up to all four sensors, depending on the experiment to be made.

In Figure 5, already shown in the Proceedings of ETOP 2007, one can see the calibration and alignment of one sensor for "instantaneous" measurement of position of a beam impinging on it. In real time, the computer gives the average position ( $\mathrm{x}$ and $\mathrm{y}$ coordinates) of a number of data and the corresponding variances. The number of data for the averages are limited and can be chosen in advance.

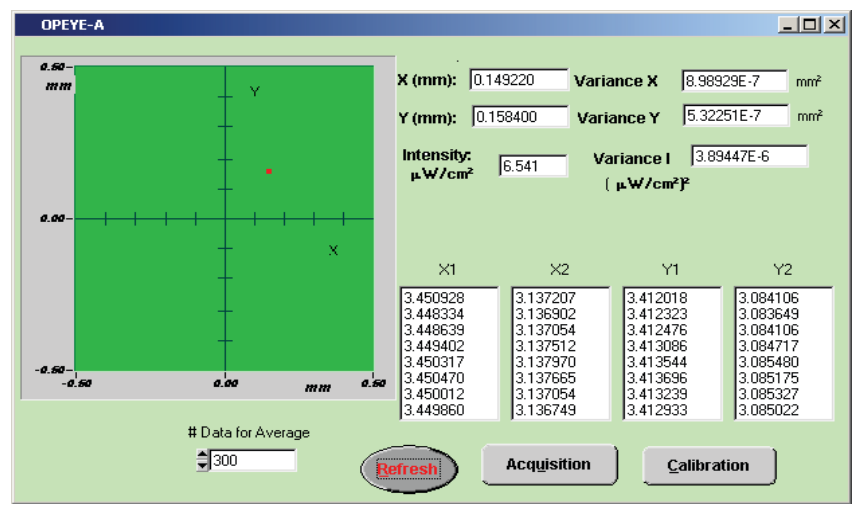

Fig. 5. Detail of the internal surface of one sensor, only the central part $(1 \mathrm{~mm} \mathrm{x} 1 \mathrm{~mm})$ is selected; scales of the axes, $-0.5 \mathrm{~mm}$ to $0.5 \mathrm{~mm}$. The four columns are the four signals directly measured by the sensor at different subsequent times. Averages and corresponding variances are presented. From A. Consortini: Using a research laboratory for training students, Proc ETOP 2007.

Advantage with respect to the previous method was incommensurable, almost tending to infinity. 


\section{USE OF COMPUTER IN TEACHING AND IN THE LABORATORY}

\subsection{Use in teaching}

When our Institute bought a personal computer (Apple) for the Secretariat, the main advantage for teaching that I experienced was redaction of notes. Initially this advantage was mainly felt by our secretary who typed the notes that we, the professors, prepared by hands. She was very happy to use the computer, instead of the usual typewriter, because she found it very easy to make corrections or to add parts, as we often required.

Subsequently, I wrote my notes directly on a small personal computer (Apple Book 100), that I bought myself. The output was on diskettes and printing was by means of the Secretariat computer. Internet was available subsequently. If I correctly remember, my first job on this matter was preparing lecture notes for the first "Winter College on Optics" at the Abdus Salam ICTP, Trieste 1993, where I taught "diffraction".

Now with internet, notes and in general textbooks can be printed and posted for the students and this is a great advantage. Internet is not a subject of this paper, however mention is to be devoted to courses and teaching through internet largely used everywhere.

Concerning students a question arises: how large is the correlation area in the mind of students when they use computers? As large as the computer screen? Sometimes, with books, it is as large as one book page...

\subsection{Use of computer in the laboratory}

Use of computer in laboratory experiments is important for teaching, mainly if the students are involved in the preparation of an experiment. In addition to the need of learning the suitable computer software, they are faced to all problems found in setting up experiments.

If they use experiments and programs already set up, there could be the risk that they simply learn how to use the apparatus without entering the problematic involved. This, however, is always a possibility, even in the simplest cases of ordinary computations.

Lectures, and in general presentation of subjects to students by computer, can be very nice and attractive, and the students become more interested in learning. However, we should avoid presenting things like they were jokes.

In addition, we should avoid that students, in describing their results, pay more attention to the "elegance and beauty" of the presentation than to the scientific results. This is of particular interest especially when they present posters to congresses. A serious risk is that the world appears virtual.

\section{NOW A BIG QUESTION}

A problem of conservation: of data, of research results, of material for the students and so on. How long will things last?
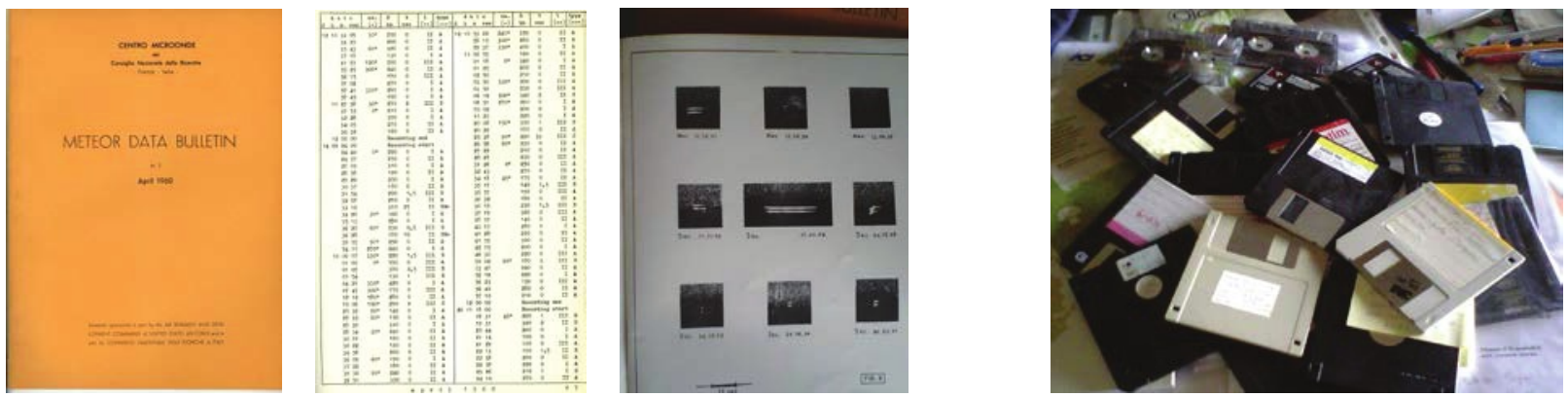

Fig. 6 Left: three samples from Meteor Data Bulletins 1960-1964, still good. Right: cassettes and diskettes no more readable. 
In Fig. 6 examples of data conservation are presented. Meteor data bulletins were simple publications, describing the data on meteor trails recorded by the radar of the Centro Microonde of CNR, (now IFAC-CNR). A copy was printed every month until 1964 and distributed to Astronomical Observatories and other Institutions. I was the organizer of the Bulleting in the last two years. After more than 50 years these data still last good. The photo on the right of Fig. 6 shows personal magnetic tapes and diskettes no more readable. Of course I have transferred somewhere some important files, but much material, especially large amount of data from measurements, are lost.

\subsection{Conservation of old text in libraries}

Everywhere in the world there are plenty of old documents. In Italy and in particular in Florence, e.g. in the National Library, in the Biblioteca Marucelliana and many others, there are precious, ancient, also hand-written, documents.

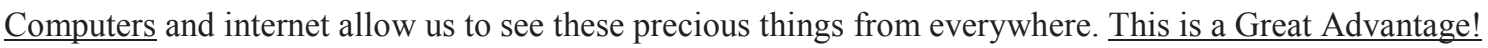

For instance, Fig 7 represents the digitized frontispiece and some pages of a book by Galileo Galilei, entitled: "Intorno alle cose che stanno in su l'acqua o in quella si muovono" (roughly: About things that float on top of the water or move in it). The book was printed by typographer Giunti, in 1612, in Florence and it is dedicated to the Grand Duke of Tuscany, Cosimo II.

The three pages of Fig.7 next the frontispiece are the first page, and the "imprimatur" page. For those who do not know, Latin world "imprimatur" documented the permission, from the religious authorities, to print it !

I have first chosen this book because it is 400 years old. However, it is not the only original copy.

In different libraries of Italy I have found 7 more volumes of the first edition (this one) and 5 volumes of the second edition, published by the same typographer in the same year.
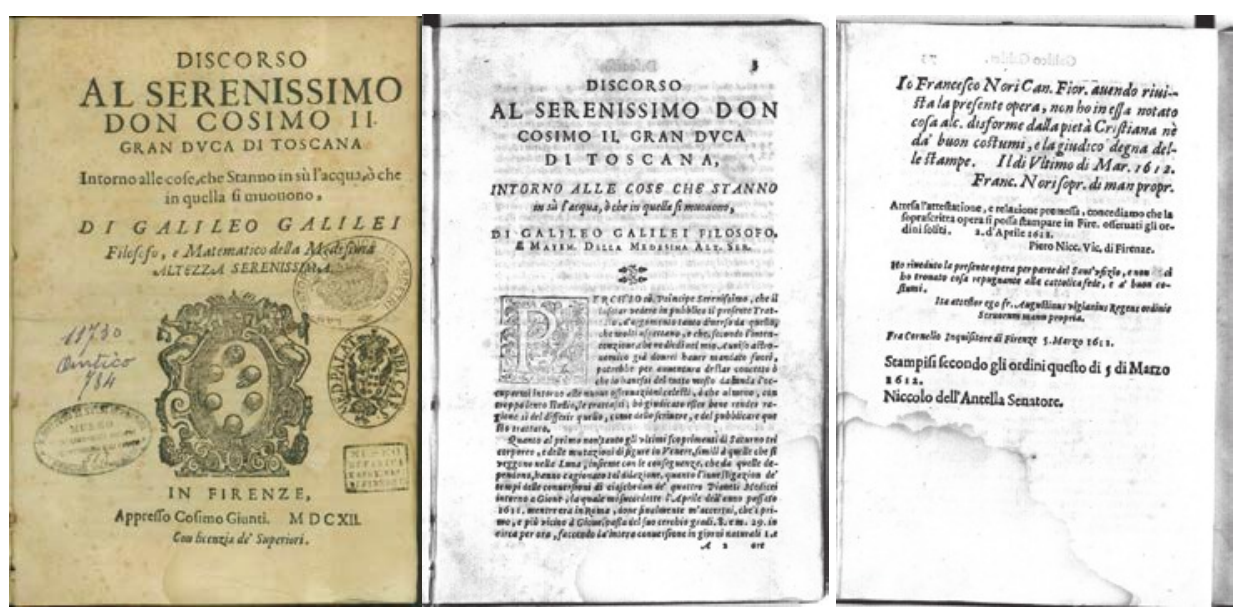

Fig.7 Frontispiece and two pages of a book of Galileo. Acknowledgements: Library of Sciences, Università degli Studi di Firenze, and Digital Library, Museo Galileo- Institute and Museum of the History of Science, IMSS, Firenze, Italy

\section{CONCLUSIONS}

Introduction of computers marked a big difference between the no-computer era. Computers have evolved strongly in time allowing many different uses.

In my 50 years of scientific activity, I have experienced an increasing capability of the computers, so that things that were not possible or very difficult to do before, became suddenly possible and easy. 
For the future, there is the important problem of conservation, because of the weakness of the support. At present, this seems a very difficult point to overcome. Of course, one could think to print the most important results, but this requires to go just in the opposite direction as now, when, for instance, many newspapers and also scientific journals are on line. In addition, there is an enormous production due just to computers.

Moreover, even when the support is good, you need a suitable instrument to read it. As technology is rapidly developing, many of them become obsolete with the same rapidity.

The originals of the ancient documents were on different materials, such as on stone, marble, wood, ceramics, metal, papyrus, paper or similar supports. With our eyes we are able to read them directly on the original version.

Going back to Galileo and something very interesting for us, Fig.8 represents the frontispiece of the famous "Dialogo dei Massimi sistemi", or more exactly "Dialogo di Galileo Galilei Linceo matematico sopraordinario dello Studio di Pisa ...; doue ne i congressi di quattro giornate si discorre sopra i due massimi sistemi del mondo tolemaico e copernicano; proponendo indeterminatamente le ragioni filosofiche, e naturali, tanto per l'vna quanto per l'altra parte'"

The uniform title, in Italian, is " DIALOGO SOPRA I DUE MASSIMI SISTEMI DEL MONDO TOLEMAICO E COPERNICANO".

The English title "Dialogue concerning the two chief world systems Ptolemaic and Copernican" is the title of the translation by Stillman Drake, with foreword by Albert Einstein, Univ. Calif. Berkley, 1967.

The book was published in Firenze (Fiorenza), by Gio. Batista Landini, in 1632. In Fig.8, in addition to the frontispiece, there are also the first page and the last one "errata corrige" !
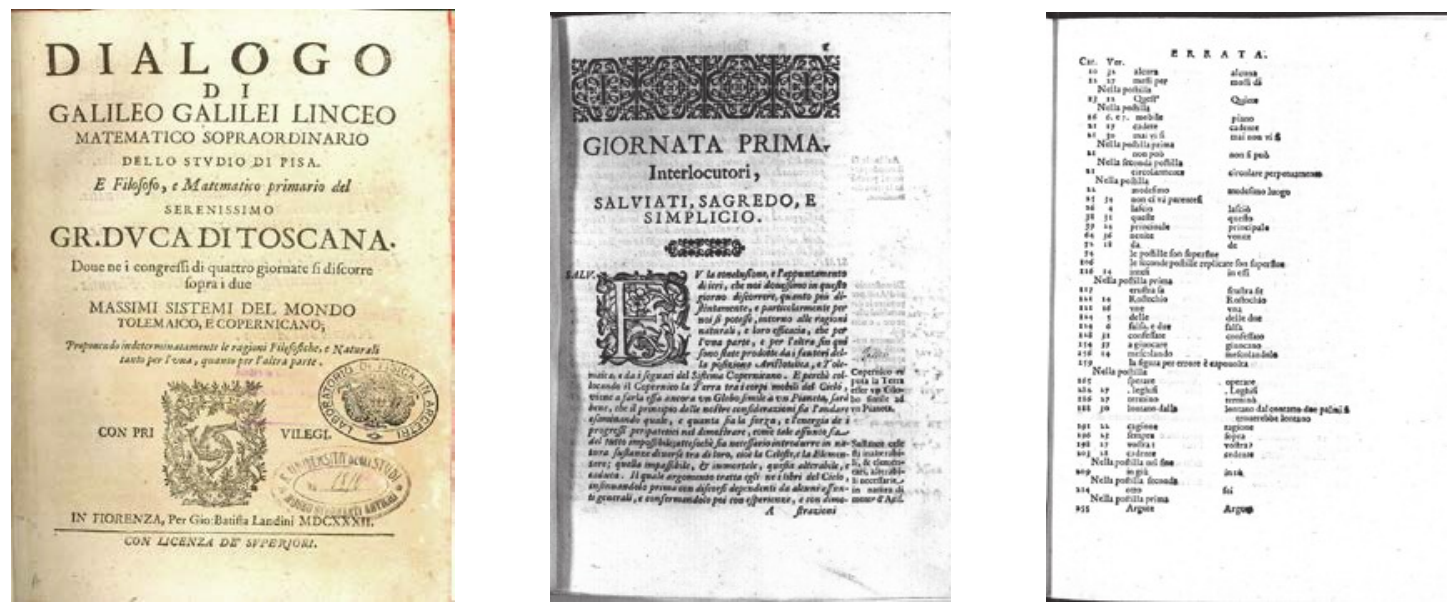

Fig.8. Galileo Galilei: "Dialogo dei massimi sistemi”, 1932: Frontispiece and two pages Acknowledgements: Library of Sciences, Università degli Studi di Firenze (University of Florence) and Digital Library, Museo Galileo- Institute and Museum of the History of Science, IMSS, Firenze, Italy.

Of this famous book, that produced so many problems to Galileo with the Church, there is a great number of original volumes. Without the sake of completeness, I have found 23 of them in the Catalogue of the Italian Libraries. A few only are not in perfect conditions or lacking some pages..

So, for now, direct knowledge not only of this important document, but also of many, many originals even manuscripts, of the past, will continue and these precious documents will survive until there will be originals. Computers will allow everyone to see digitized copies. And originals will be also seen by eyes!

Let us hope that many important originals of the present time will last too. 